Int. J. Odontostomat., 9(3):427-435, 2015.

\title{
Virus Papiloma Humano en Cáncer Oral y Orofaríngeo. Revisión de la Literatura
}

\author{
Human Papilloma virus in Oral and Oropharyngeal Cancer. Review of the Literature
}

\author{
William Contreras ${ }^{* * *}$ \& Bernardo Venegas ${ }^{* * *, * * *}$
}

CONTRERAS, W. \& VENEGAS, B. Virus papiloma humano en cáncer oral y orofaríngeo. Revisión de la literatura. Int. J. Odontostomat., 9(3):427-435, 2015.

RESUMEN: Estudios recientes demuestran una realidad prácticamente ineludible que manifiesta que el Virus Papiloma Humano (VPH) puede estar asociado al desarrollo del Carcinoma de Células Escamosas en cavidad oral y orofarínge. Desde el descubrimiento en 1974 por parte de zur Hausen et al., quienes ayudaron a definir el mecanismo por medio del cual el VPH provoca la transformación del queratinocito normal a un estado maligno, han sido numerosos los estudios que han descrito la presencia del VPH en carcinomas de cabeza y cuello, específicamente en cavidad oral y orofarínge. La detección del virus en estos carcinomas podría tener implicaciones clínicas importantes en el pronóstico y tratamiento de estos tumores, con resultados más favorables para el paciente; así mismo, justificar planes de prevención orientados al diagnóstico temprano y a la protección específica contra el VPH. Actualmente están en desarrollo terapias experimentales mínimamente invasivas que potencian el sistema inmunitario para atacar estos tumores, sin embargo, aún no están aprobadas para su uso general. En Chile todavía no existen estudios que describan la situación actual del VPH con respecto al Carcinoma de Células Escamosas en cavidad oral y orofarínge que pudieran orientar al sistema de salud con respecto a la prevención y tratamiento de este tipo de cáncer. En esta revisión presentamos los principales aspectos que relacionan al virus con este tipo de carcinoma. Se revisaron artículos indexados en inglés (Pubmed, Scopus, Cochrane Library, Google Scholar) y español (SciELO, Google Scholar), con el objetivo de brindar al Odontólogo general y especialistas una información actualizada sobre este tema, tanto desde su epidemiología como desde los mecanismos de acción carcinogénica del virus, técnicas de diagnóstico avanzadas, además, formas de prevención y estado del arte en materia de tratamiento.

PALABRAS CLAVE: carcinoma de células escamosas oral, carcinoma de células escamosas orofaríngeo, cáncer de cabeza y cuello, virus papiloma humano.

\section{INTRODUCCIÓN}

El Carcinoma de Células Escamosas (CCE) es una neoplasia que se desarrolla en epitelios estratificados planos y es en cuello uterino en donde ha tomado mayor relevancia su estudio en los últimos años. Con las investigaciones realizadas y el posterior descubrimiento de Harald zur Hausen con respecto a la estrecha relación entre el Virus Papiloma Humano (VPH) como un factor de riesgo para el desarrollo de cáncer de cuello uterino, se demostró que este virus juega un importante papel en la transformación de las células a un estado maligno (zur Hausen et al., 1974; zur Hausen, 1976).
Syrjänen et al. (1983) fueron los primeros en proponer al VPH como factor de riesgo en el desarrollo de CCE de cabeza y cuello. En cavidad oral y orofarínge se han realizado investigaciones con el objetivo de identificar la presencia del virus con múltiples técnicas diagnósticas y se ha detectado que a similitud del cuello uterino, uno de los factores principales de riesgo es el VPH, el cual puede estar relacionado con la carcinogénesis en este tejido que comparte las mismas características histológicas que las de la mucosa del cuello del útero. Sin embargo, no es hasta el 2010 que el panel de expertos de la Asociación

\footnotetext{
Alumno, Programa de Magíster en Ciencias Biomédicas mención Patología Oral, Universidad de Talca, Talca, Chile.

* Becario, Programa de Becas de Cooperación Horizontal AGCI, Chile.

*** Unidad de Patología Oral, Departamento de Estomatología, Facultad de Ciencias de la Salud, Universidad de Talca, Talca, Chile.

How** Hospital Carlos van Buren, Valparaíso, Chile.
} 
Dental Americana (ADA) reconoce al VPH como un factor de riesgo en el desarrollo de cáncer orofaríngeo (Rethman et al., 2010).

El objetivo de esta revisión fue evaluar y presentar los artículos de mayor relevancia que puedan brindar información detallada al profesional de la Estomatología sobre la carcinogénesis del virus, diagnóstico y estado del arte en materia de prevención y tratamiento del CCE asociado al VPH.

\section{MATERIAL Y MÉTODO}

Se analizaron las bases de datos PubMed, Scopus, Cochrane Library, Google Scholar (Inglés), SciELO y Google Scholar (Español) en búsqueda de estudios o artículos con las siguientes palabras clave en inglés: Oral Squamous Cell Carcinoma, Oropharyngeal Squamous Cell Carcinoma, Head and Neck Cancer, Human Papillomavirus, y en español: Virus Papiloma Humano, Cáncer Oral, Cáncer Orofaríngeo, Carcinoma de Células Escamosas, Cáncer de Cabeza y Cuello.

Se incluyeron revisiones sistemáticas así como estudios retrospectivos. No se consideraron casos clínicos ni abstracts. La búsqueda se realizó a partir del año 2000 hasta mayo del 2015.

\section{RESULTADOS}

Epidemiologia del CCE oral y orofaríngeo. Él carcinoma de células escamosas (CCE) ocupa el $90 \%$ de todas las neoplasias malignas en la cavidad oral y la orofarínge. El sexo masculino es el más afectado, lo cual se asocia a un mayor consumo de alcohol y taba$\mathrm{co}$, tanto en frecuencia como en cantidad. En el año 2000 se registraron 389.650 casos de CCE, de los cuales 266.672 estaban localizados en la cavidad oral y 122.978 en la orofarínge (Barnes et al., 2005). En el año 2008 hubo 263.900 casos nuevos y 128.000 muertes debido a éste cáncer (Itriago et al., 2013). El CCE de cavidad oral y orofaringe representa el $5 \%$ de todos los cánceres en el hombre y el $2 \%$ en la mujer (Barnes et al.). En los Estados Unidos esta neoplasia contabiliza el $3 \%$ de todos los cánceres y es el octavo más común en hombres (Neville et al., 2009). A nivel mundial ocupa el decimoprimer puesto entre los cánceres más comunes, con una alta incidencia en paí- ses como India, Australia, Francia, Brasil y el sur de África (Neville, et al.).

En Latinoamérica la información es escasa y son pocos los estudios específicos que puedan proveer de datos con respecto al CCE y más aún con relación al VPH (Anaya-Saavedra et al., 2008; Ruiz et al., 2009). En Chile, un estudio efectuado en 2005 para evaluar la morbilidad y mortalidad por cáncer oral y orofaríngeo mostró que éste representa el $1 \%$ respecto de todos los cánceres y el $90 \%$ de las neoplasias malignas en cavidad oral y orofarínge son carcinomas de células escamosas, siendo la lengua el sitio más frecuente de localización (Riera \& Martínez, 2005). Más recientemente Ramirez et al., (2015) evaluaron la mortalidad en el período 2002-2010 en Chile, confirmando algunos datos ya mencionados por Riera \& Martínez, por ejemplo, la lengua sigue siendo el lugar predilecto de aparición de la neoplasia seguido por orofarínge y glándulas salivales mayores. La tasa de mortalidad fue de 1,11 a 1,25 por 100.000 habitantes. Así mismo describen que es a partir de los 55 años de edad donde se concentra la mayor mortalidad de este cáncer con una relación hombre mujer de 2,3:1.

Virus Papiloma Humano (VPH). El virus papiloma humano (VPH) es una familia de pequeños virus ADN de doble cadena que infectan el epitelio plano estratificado tanto de la piel como de mucosas (de Villiers et al., 2004). Existen alrededor de 100 tipos de virus papiloma que pueden infectar al ser humano (de Villiers et al.), existiendo tipos que poseen un alto riesgo oncogénico (Gonzalez-Losa et al., 2008). En el año 1995 la Agencia Internacional para la Investigación sobre el Cáncer (IARC) clasificó los tipos de VPH 16 y 18, como agente carcinógeno humano debido a las oncoproteínas codificadas en su ADN capaces de desregular el ciclo celular (Muñoz et al., 2003; IARC, 2007). Con respecto a la prevalencia a nivel mundial de infección del VPH esta alcanza un $45,8 \%$ en orofarínge y $24,2 \%$ en cavidad oral (Ndiaye et al., 2014) y es el VPH-16 el más prevalente (Martin et al., 2014).

Estructura del VPH. El virus papiloma humano (VPH) es un virus perteneciente a la familia Papillomaviridae, de tipo icosaédrico sin manto. Se han secuenciado los genomas de aproximadamente 150 tipos de VPH y esto ha permitido dividirlos en cinco géneros (Alfa, Beta, Gamma, Nu y Mu), de los cuales el grupo Alfa es el grupo más significativo para el desarrollo de lesiones a nivel cutáneo o mucoso (Powell \& Evans, 2015). La Organización Mundial de la Salud (OMS) ha definido doce tipos de VPH como de Alto Riesgo cau- 
santes de cáncer $(16,18,31,33,35,39,45,51,52$, 56,58 y 59) (Powell \& Evans). Este virus mide $55 \mathrm{~nm}$ y poseen un genoma de ADN circular de aproximadamente 8 mil pares de bases (Avendaño et al., 2011).

El genoma del virus codifica ocho genes que se clasifican de la siguiente manera: Seis regiones tempranas (E1 a E7), dos regiones tardías (L1 y L2) y una Región Larga de Control (LCR).

Los genes del grupo temprano (Grupo E) son los responsables de la replicación, transcripción y transformación, mientras que los del grupo tardío (Grupo L) son los que codifican la información para la formación de proteínas de la cápside viral. La Región Larga de Control (LCR) como su nombre lo indica, contiene elementos que regulan la replicación y la transcripción (García-Cuellar et al., 2009; Avendaño et al.) (Fig. 1).

Los genes tempranos E6 y E7 codifican para una proteína de 160 aminoácidos y un polipéptido de 100 aminoácidos respectivamente (Avendaño et al.).

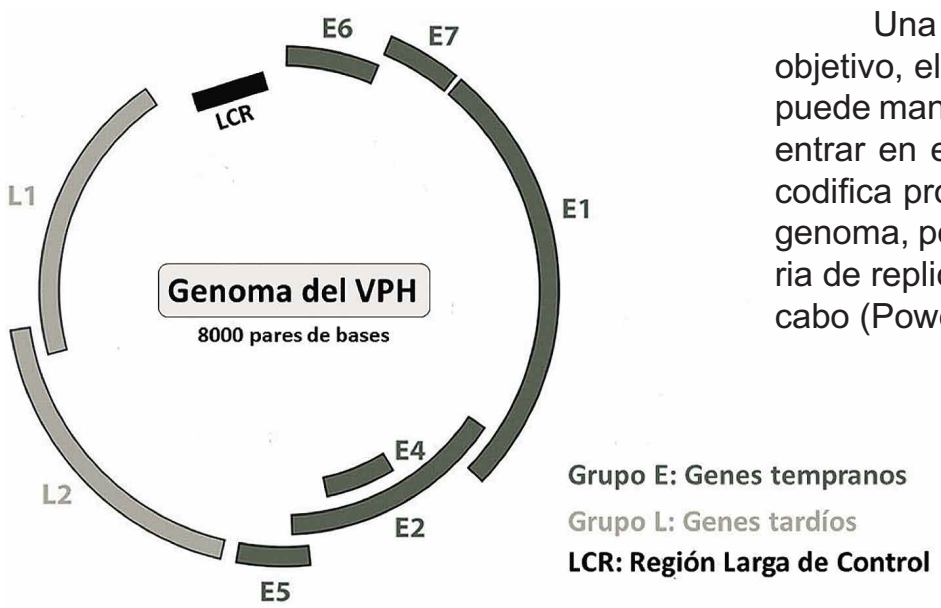

Fig. 1. Estructura genómica del VPH de alto riesgo.

Tabla I. Proteínas virales del VPH y su respectiva función.

\begin{tabular}{|c|c|}
\hline Proteína Viral & Función \\
\hline E1 & $\begin{array}{l}\text { Acción helicasa. Replicación viral y control de la transcripción. Dependiente de ATP (Graham, 2010; } \\
\text { Grillo-Ardila et al., 2008). }\end{array}$ \\
\hline E2 & Factor de transcripción viral. Regulación de la expresión génica celular.(Graham; Grillo-Ardila et al.). \\
\hline E4 & Interacción con el citoesqueleto y remodelación de citoqueratinas (Graham; Grillo-Ardila et al.). \\
\hline E5 & Interacción con receptores de factores de crecimiento. Modulación inmune (Graham; Grillo-Ardila et al.). \\
\hline E6 & $\begin{array}{l}\text { Oncoproteína. Degradación de p53. Inhibición de apoptosis. Modificación de polaridad y morfología } \\
\text { celular. Activación de telomerasa (Graham; Grillo-Ardila et al.). }\end{array}$ \\
\hline E7 & $\begin{array}{l}\text { Oncoproteína. Interacción con pRb e inactivación de ésta. Inestabilidad genómica. Desregulación de ciclo } \\
\text { celular (Graham; Grillo-Ardila et al.). }\end{array}$ \\
\hline L1 & Proteína mayor cápside viral (Graham; Grillo-Ardila et al.). \\
\hline L2 & $\begin{array}{l}\text { Proteína menor cápside viral. Recluta genoma viral para organizarlo en la cápside (Graham; Grillo-Ardila } \\
\text { et al.). }\end{array}$ \\
\hline
\end{tabular}

Estos son conocidos como oncoproteínas, debido a que son las responsables de provocar la desregulación del ciclo celular, inmortalización y el crecimiento desmedido en el queratinocito, teniendo como resultado la malignización de la célula (Tabla I).

Mecanismos de Infección y Carcinogénesis del VPH. El primer evento para realizar la infección por parte del VPH se lleva a cabo en el estrato basal del epitelio. El virus debe llegar hasta este estrato para que las proteínas de la cápside (L1) puedan entrar en contacto con receptores de superficie celular (Giroglou et al., 2001). Para que el VPH ingrese a este estrato necesita alguna disrupción o trauma en el tejido, ya que si el epitelio se mantiene íntegro, el virus será incapaz de llegar hasta su lugar de acción. La cavidad oral y orofarínge son sitios ideales para la infección, ya que son regiones propensas a los microtraumas por efecto de actividades fisiológicas normales que en conjunto con relaciones sexuales oro-genitales con personas portadoras, convierten a estas regiones en sitios aptos al ataque repetido del virus (GonzalezLosa et al.; Bharti et al., 2013).

Una vez el virus entra en contacto con la célula objetivo, el ADN viral llega hasta el núcleo, en donde puede mantenerse en estado de reposo o episomal, o entrar en estado de transcripción activa. El VPH no codifica proteínas que realicen la transcripción de su genoma, por lo que depende de la mitosis y maquinaria de replicación de la célula huésped para llevarla a cabo (Powell \& Evans). 
Dentro de los mecanismos carcinogénicos utilizados por el VPH para lograr la transformación celular, se describen las proteínas E6 y E7 como responsables del proceso de malignización. Una vez que el ADN viral se integró al de la célula huésped se pierde la proteína E2 del virus (encargada de la regulación transcripcional) y como consecuencia se sobre-expresan las oncoproteínas E6 y E7. Estas dos proteínas son sintetizadas con el objetivo de bloquear los puntos de control en el ciclo celular, evadiendo así los mecanismos de quiescencia o apoptosis endógenos que son llevados a cabo por proteínas supresoras de tumores (Sapp et al., 2005) (Fig. 2).

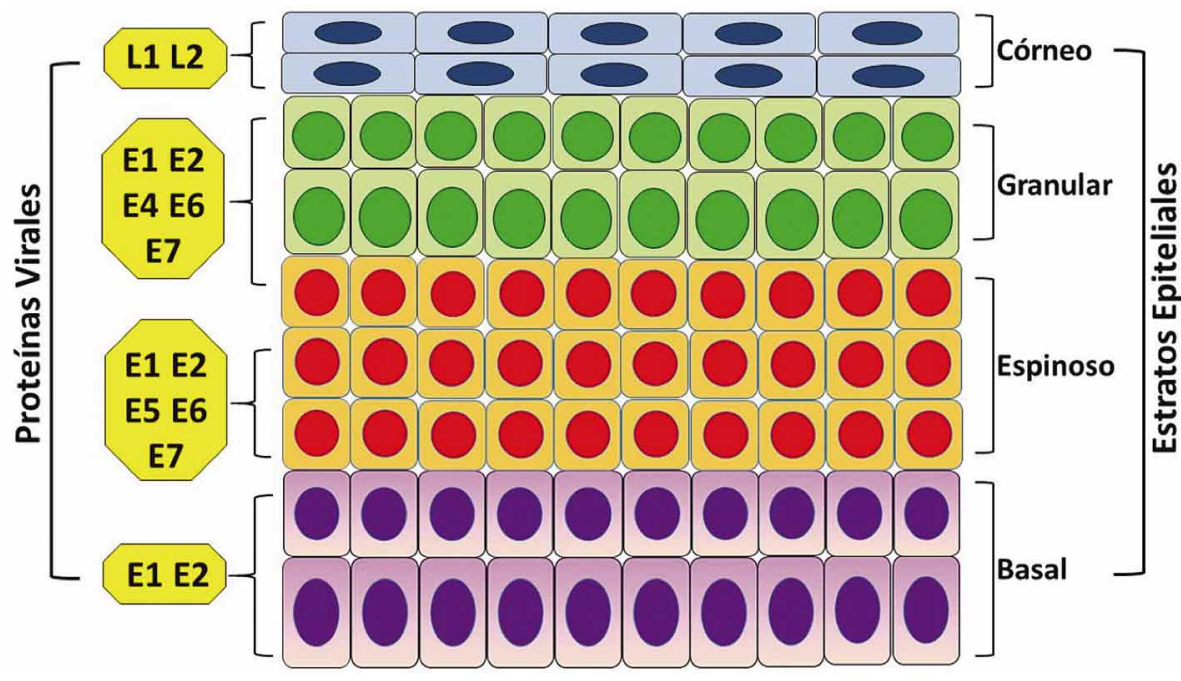

Fig. 2. Proteínas del VPH de alto riesgo y correspondiente lugar de acción en el epitelio escamoso estratificado.

Oncoproteína E7. La proteína E7 es una proteína de aproximadamente 13 KDa localizada principalmente en el núcleo, capaz de unirse a la proteína supresora de tumores Retinoblastoma ( $p R b)$ y alterar su función en la fase G1-S del ciclo celular (Powell \& Evans). La interacción de E7 con pRb, permite la liberación del factor de transcripción E2F, promoviendo así la transcripción de genes relacionados con la proliferación celular y la síntesis de ADN (zur Hausen, 2000; Rivera et al., 2006; Powell \& Evans). Otro de los efectos que provoca E7 en el ciclo celular es la sobre-expresión sin efecto alguno de p16INK4a, la cual, en condiciones de normalidad mantiene en estado hipofosforilado a pRb evitando la liberación de E2F, logrando frenar la multiplicación de las células y la progresión del ciclo (zur Hausen, 2000).

Oncoproteína E6. La proteína E6 es una proteína de aproximadamente $18 \mathrm{KDa}$ capaz de formar un complejo con la proteína p53 por medio de una ubiquitinaligasa y así degradarla por vía proteosomal, evitando así el punto de control en el ciclo celular en la fase G1, logrando así, la evasión la apoptósis. Otra de sus propiedades es la capacidad de inhibir acetiltransferasas de histonas, que acetilan y estabilizan a p53 (Powell \& Evans). También puede interactuar con otras proteínas que están involucradas en actividades de transformación de la célula, por ejemplo: co-activadores transcripcionales, proteínas involucradas en la polaridad y motilidad celular, supresoras de tumores e inductoras de apoptosis, factores de reparación y replicación de ADN (IARC). Así mismo, E6 cuenta con algunas funciones independientes que promueven la formación tumoral incluida la promoción de la activación indirecta de la telomerasa e interacción con proteínas PDZ relacionadas a uniones celulares y estructuras del citoesqueleto (Powell \& Evans) (Fig. 3).

\section{Implicancia Clínica y Pronóstica del VPH en CCE Oral y Orofaríngeo. En algu- nos países del mundo se ha encontrado fuerte correlación entre el VPH, cáncer oral y orofaríngeo (Elango et al., 2011; Khangura et al., 2013; Patil et al., 2014) con tenden- cia al alza en incidencia, pro- bablemente por cambios en comportamientos sexuales.}

La literatura informa que el $17,8 \%$ de todos los cánceres son provocados por agentes de tipo infeccioso y el $12,1 \%$ corresponde a virus, esto obliga a investigar más al respecto al VPH como agente carcinógeno y su participación en el CCE en cavidad oral y orofarínge (Álvarez Aldana et al., 2012). En Chile se tiene evidencia de evaluación de CCE asociado a VPH en regiones esofágicas, sin embargo, existen pocos estudios relacionados a VPH fuera de los cánceres ginecológicos.

La mayor implicancia que podría tener el VPH con respecto a esta neoplasia radica en los estudios que sugieren que los tumores positivos para la presencia de VPH tienen un mejor pronóstico que los negativos para el virus, y la reducción de muerte podría llegar a ser de hasta el $60 \%$ u 80\% (Fakhry \& Gillison, 2006). Así mismo se justificarían planes preventivos como medida de control del factor de riesgo. 


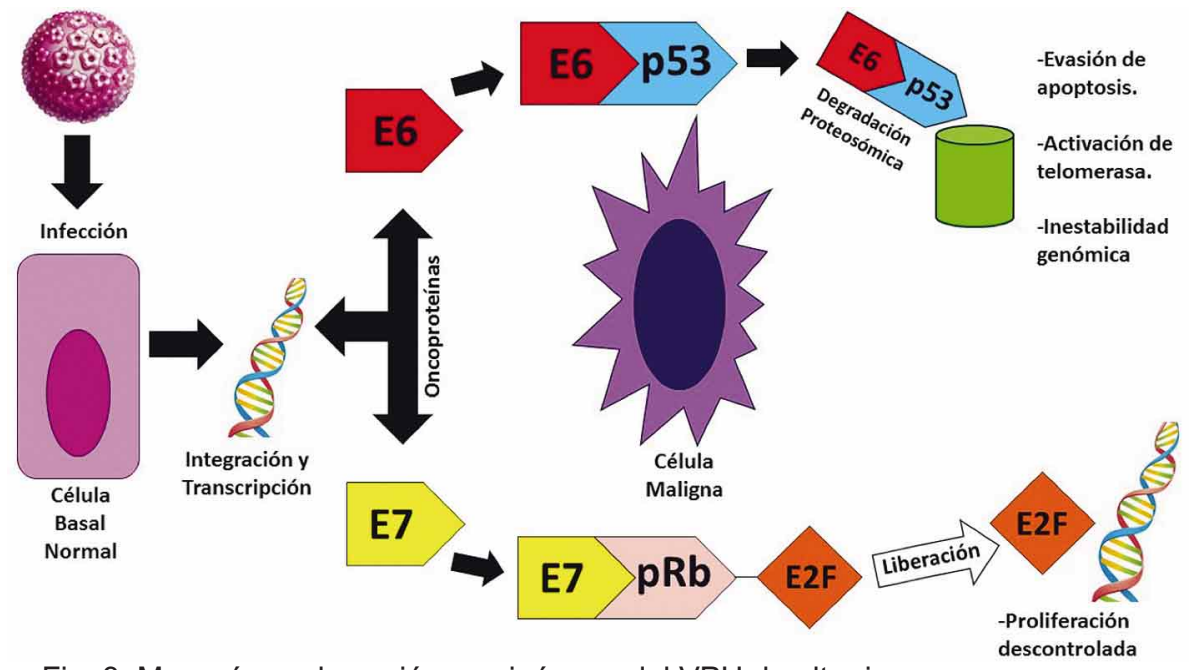

Fig. 3. Mecanísmo de acción carcinógena del VPH de alto riesgo.

Técnicas diagnósticas para la detección del VPH de alto riesgo en CCE. La microscopía óptica es el paso inicial para evaluar CCE y se menciona en la literatura que el patrón morfológico de invasión puede ser una característica relevante para diferenciar inicialmente un CCE asociado a VPH. Westra (2014) y Bishop (2015) mencionan entre las características microscópicas que la transición entre epitelio sano y epitelio neoplásico relacionado a VPH se da de manera abrupta sin zonas precursoras de malignidad, es decir, no se presenta la secuencia de etapas características de displasia que culminan en Carcinoma in situ o Carcinoma invasivo, lo cual es común en CCE no asociados a VPH. Así mismo, se mencionan algunos cambios citomorfológicos que pueden hacer suponer al observador que está en presencia de la neoplasia asociada al virus, los cuales son: radio núcleo-citoplasma aumentado, citoplasma sincitial sin puentes intercelulares, poca queratinización citoplasmática y apariencia basaloide. La correcta detección de estos cambios puede ayudar a iniciar estudios moleculares específicos que permitan detectar con mayor precisión la presencia del VPH (Bishop).

La detección del VPH en células tumorales de CCE por medios moleculares se puede llevar a cabo por varias técnicas que identifican el ADN del virus como son: qRT-PCR (reacción en cadena de la polimerasa por transcriptasa reversa cuantitativa) e Hibridación in Situ, los cuales a pesar de ser técnicas muy eficaces, detectan el ADN viral y el ARNm de oncoproteínas, pero tienen como desventaja su alto costo, necesidad de muestras congeladas (en caso de qRT-PCR considerado el gold standard), aparatos, instrumental y personal altamente capacitado para realizar estos análisis (Serena-Gómez et al., 2011; Martínez Martínez et al., 2014). En los últimos años se ha investigado por medio de técnicas aplicables al laboratorio diagnóstico y es así como surgen dos opciones: inmunohistoquímica de proteínas relacionadas indirectamente al virus de alto riesgo (proteína p16INK4a) que tiene como ventaja su alta sensibilidad y buena especificidad (Thomas \& Primeaux, 2012; Dreyer et al., 2013; Agrawal et al., 2013; Patil et al.; Moutasim et al., 2015), y más recientemente la Hibridación In Situ para detección de ARNm de E6/E7 de nombre comercial RNAscope HPV-test ${ }^{\circledR}$ (Advanced Cell Diagnostics, Inc. Hayward, CA, USA), cuyo desempeño es comparable al del qRT-PCR, y es apta para ser utilizada en tejidos embebidos en parafina (Mirghani et al., 2015). Se ha planteado que la identificación del virus en el tumor debiera ser obligatoria como parte del diagnóstico, ya que la presencia del VPH podría cambiar el comportamiento de las células malignas, haciéndolas menos invasivas y por lo tanto hacer más favorable el pronóstico de la enfermedad. Cabe destacar que el Colegio de Patólogos Americanos ha recomendado recientemente evaluar la presencia de VPH como examen rutinario patológico en biopsias de CCE de orofarínge (Piña-Sánchez \& Alvarado-Cabrero, 2012; Robinson et al., 2012; Duncan et al., 2013; Deng et al., 2014; El-Mofty, 2014; Maniakas et al., 2014; Westra).

Prevención de CCE asociado a VPH. Uno de los principales problemas del CCE en cavidad oral y orofarínge radica en que su detección y diagnóstico se da la mayoría de veces en etapas avanzadas, esto debido a los pocos síntomas que produce o a errores diagnósticos, haciendo su tratamiento más complejo e invasivo 
y su pronóstico reservado. Sin embargo, al ser estas zonas, regiones expuestas y accesibles a la exploración clínica por parte del facultativo previamente formado, la prevención por medio de un examen clínico se vuelve clave en la detección y diagnóstico precoz de CCE en estas áreas.

En países como Cuba la experiencia de prevención por medio de programas nacionales de detección ha tenido gran impacto tanto en mantener la curabilidad, como en la reducción de la mortalidad, justificando la necesidad de implantar este tipo de actividades por medio de entidades de salud pública en Latinoamérica (Morales Navarro et al., 2009).

En la actualidad existen dos vacunas comerciales de este tipo aprobadas por la Administración de Drogas y Alimentos de los Estados Unidos de América (FDA). Gardasil[ (Merck \& Co., Inc. Estados Unidos), vacuna cuadrivalente que protege contra VPH de bajo riesgo 6 y 11 y $\mathrm{VPH}$ de alto riesgo 16 y 18 , mientras que Cervarix ${ }^{\circledR}$ (GlaxoSmithKline, Reino Unido) de tipo bivalente ya que únicamente protege de los VPH de alto riesgo 16 y 18 . El principio activo de estas radica en que, al ser Particulas Semejantes al Virus (PSV) actúan como antígenos para el sistema inmune de memoria, permitiendo que el individuo esté inmunizado contra elvirus. Ambas vacunas han presentado altos índices de eficacia ( $98 \%$ y $97 \%$ respectivamente) en la prevención de lesiones precancerosas anales, vulvares, vaginales y cervicales (Psyrri et al., 2012). La teoría indica que estas vacunas profilácticas podrían ser útiles en la prevención especifica en caso de infección por VPH de alto riesgo, y por ende, contribuirían en la disminución de la incidencia de CCE en cavidad oral y orofarínge; sin embargo, aún no se tienen datos claros y relevantes sobre el impacto de este método de prevención con respecto al cáncer en las áreas mencionadas.

Tratamientos experimentales. En los casos de CCE, la resección quirúrgica de la lesión acompañada de cadena linfática sigue siendo el tratamiento de elección en la actualidad, en asociación a coadyuvantes de quimioterapia y radioterapia. Actualmente se están desarrollando nuevos tratamientos a nivel experimental con resultados alentadores en aquellos CCE en los cuales se detecta la presencia de VPH de alto riesgo.

En el grupo de más promisorias se menciona a las vacunas elaboradas a partir de la sustitución de aminoácidos en posiciones clave en el ADN del antígeno E7 para prevenir la malignización de las cé- lulas. Una vez realizada esta operación se utiliza una estrategia de marcaje en la cual se conjuga el antígeno E7 con una molécula estimulante del sistema inmune llamada calreticulina (CRT). Cuando la conjugación es realizada la secuencia es insertada en un plásmido para que exprese la proteína-antígeno, provocando una respuesta inmunitaria. Cabe mencionar que esta vacuna debe ser administrada por medio de electroporación y acompañada de inmunosupresores como ciclofosfamida (Psyrri et al.).

Otra de las alternativas que actualmente ha tomado importancia en el grupo de vacunas terapéuticas, son las vacunas de péptidos derivadas de proteínas antigénicas de VPH. El principio de estas vacunas se basa en el reconocimiento del antígeno inyectado por parte de células presentadoras de antígenos (células dendríticas) y su posterior presentación por medio del Complejo Mayor de Histocompatibilidad (MHC). Los principales péptidos utilizados (de manera experimental aún) en la actualidad son: p16INK4a (conocida como p16) y secuencias de péptidos de E6 y E7 traslapadas.

La principal desventaja de estas vacunas peptídicas radica en la pobre respuesta inmunitaria que provocan, haciendo necesaria la utilización de auxiliares que potencien la respuesta de células presentadoras, como por ejemplo el Factor Estimulante de Colonias de Macrófagos y Granulocitos (GM-CSF) y Montanide ISA-51 (Psyrri et al.).

\section{CONCLUSIÓN}

La relación del VPH con el CCE oral y orofaríngeo según los estudios más recientes se presenta como una realidad actual y debe ser catalogada como una entidad diferente al CCE convencional. Es imprescindible que los equipos multidisciplinarios de salud y en especial los Cirujanos Dentistas cuenten con información actualizada sobre el virus como factor de riesgo con el fin de investigar de manera exhaustiva la situación actual del virus en estos carcinomas en Chile, lo anterior considerando que aún no existen investigaciones que describan esta situación. La importancia de llevar a cabo estas investigaciones es dilucidar el papel que podría jugar el VPH en los CCE orales y de orofarínge, para de esta manera proponer planes o estrategias de prevención basados en la evidencia hallada a través de los resultados obtenidos. Las herramientas preventivas y tera- 
péuticas más innovadoras están apelando a la mínima invasión, utilizando la respuesta inmunitaria como protección específica o como tratamiento en estadios tempranos de la neoplasia con resultados alentado- res; sin embargo, se requiere de más investigación para probar su efectividad en el territorio oral y orofaríngeo ya sea como medio de protección específica o como medio terapéutico coadyuvante.

CONTRERAS, W. \& VENEGAS, B. Human papillomavirus in oral and oropharyngeal cancer. Review of the literature. Int. J. Odontostomat., 9(3):427-435, 2015.

ABSTRACT: Recent studies indicate what has become a nearly inescapable reality in that Human Papilloma Virus can be associated to the development of Oral and Oropharyngeal Squamous Cell Carcinoma. Since the discovery of zur Hausen et al. that helped define the mechanism by which HPV causes normal keratinocyte transformation to a malignant state, there have been numerous studies that have described the presence of HPV in head and neck carcinomas, specifically in oral cavity and oropharynx. The detection of the virus in these carcinomas may have important clinical implications in the prognosis and treatment of these tumors with more favorable patient outcomes; likewise, justify prevention plans aimed at early diagnosis and specific protection against HPV. Currently minimally invasive experimental therapies that boost the immune system to attack these tumors are in development, however, they are not yet approved for general use. In Chile there are no studies that describe the current situation with regard to HPV Squamous Cell Carcinoma in oral cavity and oropharynx that may guide the health system regarding the prevention and treatment of this cancer. In this review we present the principal aspects that associate the virus with this type of oral and oropharyngeal carcinoma. We reviewed indexed articles in English (Pubmed, Scopus, Cochrane Library, Google Scholar) and Spanish (SciELO, Google Scholar), with the objective to provide Dental Surgeons and specialists the most updated information about this subject. The review was developed considering the epidemiology as well as the carcinogenic mechanisms of the virus, advanced diagnostic techniques, ways of prevention and state of the art in treatment matters.

KEY WORDS: oral squamous cell carcinoma, oropharyngeal squamous cell carcinoma, head and neck cancer, human papillomavirus.

\section{REFERENCIAS BIBLIOGRÁFICAS}

Agrawal, G. P.; Joshi, P. S. \& Agrawal, A. Role of HPV-16 in pathogenesis of oral epithelial dysplasia and oral squamous cell carcinoma and correlation of p16ink4a expression in HPV-16 positive cases: $A n$ immunohistochemical study. I. S. R. N. Pathol., (807095):7p., 2013.

Álvarez Aldana, A.; Sepúlveda Arias, J. C. \& Siller López, F. Carcinogénesis inducida por el virus del papiloma humano. Investig. Andin., 14(24):438-56, 2012.

Anaya-Saavedra, G.; Ramírez-Amador, V.; IrigoyenCamacho, M. E.; García-Cuellar, C. M.; Guido-Jiménez, M.; Méndez-Martínez, R. \& García-Carrancá A. High association of human papillomavirus infection with oral cancer: a case-control study. Arch. Med. Res., 39(2):189$97,2008$.

Avendaño, L. F.; Ferrés, M. \& Spencer, E. Virología Clínica. Santiago, Chile, Editorial Mediterráneo, 2011. pp.188-91.

Barnes, L.; Eveson, J. W.; Reichart, P.; Sidransky, D. Pathology and Genetics of Head and Neck Tumours. World Health Organization Classification of Tumours. Lyon, IARC press, 2005.
Bharti, A. H.; Chotaliya, K. \& Marfatia, Y. S. An update on oral human papillomavirus infection. Indian J. Sex. Transm. Dis., 34(2):77-82, 2013.

Bishop, J. A. Histopathology of human papillomavirusrelated oropharyngeal carcinoma: a review of classic and variant forms. Diagn. Histopathol., 21(2):70-6, 2015.

de Villiers, E. M.; Fauquet, C.; Broker, T. R.; Bernard, H. U. \& zur Hausen, $\mathrm{H}$. Classification of papillomaviruses. Virology, 324(1):17-27, 2004.

Deng, Z.; Hasegawa, M.; Aoki, K.; Matayoshi, S.; Kiyuna, A.; Yamashita, Y.; Uehara, T.; Agena, S.; Maeda, H.; Xie, M. \& Suzuki, M. A comprehensive evaluation of human papillomavirus positive status and p16INK4a overexpression as a prognostic biomarker in head and neck squamous cell carcinoma. Int. J. Oncol., 45(1):6776, 2014.

Dreyer, J. H.; Hauck, F.; Oliveira-Silva, M.; Barros, M. H. \& Niedobitek G. Detection of HPV infection in head and neck squamous cell carcinoma: a practical proposal. Virchows Arch., 462(4):381-9, 2013. 
Duncan, L. D.; Winkler, M.; Carlson, E. R.; Heidel, R. E.; Kang, E. \& Webb, D. p16 immunohistochemistry can be used to detect human papillomavirus in oral cavity squamous cell carcinoma. J. Oral Maxillofac. Surg., 71(8):1367-75, 2013.

Elango, K. J.; Suresh, A.; Erode, E. M.; Subhadradevi, L.; Ravindran, H. K.; lyer, S. K.; lyer, S. K. \& Kuriakose, M. A. Role of human papilloma virus in oral tongue squamous cell carcinoma. Asian Pac. J. Cancer Prev., 12(4):889-96, 2011.

El-Mofty, S. K. Histopathologic risk factors in oral and oropharyngeal squamous cell carcinoma variants: an update with special reference to HPV-related carcinomas. Med. Oral Patol. Oral Cir. Bucal, 19(4):e377-85, 2014.

Fakhry, C. \& Gillison, M. L. Clinical implications of human papillomavirus in head and neck cancers. J. Clin. Oncol., 24(17):2606-11, 2006.

García-Cuellar, C. M.; González Ramírez, I. C. \& Granados García, M. VPH y los carcinomas de cavidad bucal y bucofaringe. Cancerol., 4:181-91 2009.

Giroglou, T.; Florin, L.; Schäfer, F.; Streeck, R. E. \& Sapp, M. Human papillomavirus infection requires cell surface heparan sulfate. J. Virol., 75(3):1565-70, 2001.

González-Losa, Mdel. R.; Manzano-Cabrera, L.; RuedaGordillo, F.; Hernández-Solís, S. E. \& Puerto-Solís, L. Low prevalence of high risk human papillomavirus in normal oral mucosa by hybrid capture 2. Braz. J. Microbiol., 39(1):32-4, 2008.

Graham, S. V. Human papillomavirus: gene expression, regulation and prospects for novel diagnostic methods and antiviral therapies. Future Microbiol., 5(10):1493506, 2010.

Grillo-Ardila, C. F.; Martínez-Velásquez, M. Y. \& MoralesLópez, B. Virus del papiloma humano: aspectos moleculares y cáncer de cérvix. Rev. Colomb. Obstet. Ginecol., 59(4):310-5, 2008.

International Agency for Research on Cancer (IARC). IARC Monographs on the Evaluation of Carcinogenic Risks to Humans. Lyon, World Health Organization, 2007.

Itriago G. L.; Silva I. N. \& Cortes F. G. Cáncer en Chile y el mundo: una mirada epidemiológica, presente y futuro. Rev. Med. Clin. Condes, 24(4):531-52, 2013.

Khangura, R. K.; Sengupta, S.; Sircar, K.; Sharma, B.; Singh, S. \& Rastogi, V. HPV involvement in OSCC: Correlation of PCR results with light microscopic features. J. Oral Maxillofac. Pathol., 17(2):195-200, 2013.
Maniakas, A.; Moubayed, S. P.; Ayad, T.; Guertin, L.; NguyenTan, P. F.; Gologan, O.; Soulieres, D. \& Christopoulos, A. North-American survey on HPV-DNA and p16 testing for head and neck squamous cell carcinoma. Oral Oncol., 50(10):942-6, 2014.

Martin, E.; Dang, J.; Bzhalava, D.; Stern, J.; Edelstein, Z. R.; Koutsky, L. A.; Kiviat, N. B. \& Feng, Q. Characterization of three novel human papillomavirus types isolated from oral rinse samples of healthy individuals. J. Clin. Virol., 59(1):30-7, 2014.

Martínez Martínez, A.; Baldiris Ávila, R. \& Díaz Caballero, A. Infección por papiloma virus humano y carcinoma escamocelular bucal, diversas técnicas moleculares para detectar su presencia. Av. Odontoestomatol., 30(2):6978, 2014.

Mirghani, H.; Amen, F.; Moreau, F. \& Lacau St Guily, J. Do high-risk human papillomaviruses cause oral cavity squamous cell carcinoma? Oral Oncol., 51(3):229-36, 2015.

Morales Navarro, D.; Rodríguez Lay, L. \& García Jordán, M. Importancia del Programa de Deteccion Temprana del cancer bucal en Cuba. Rev. Habanera Cienc. Méd., 8(4):0p., 2009.

Moutasim, K. A.; Robinson, M. \& Thavaraj, S. Human papillomavirus testing in diagnostic head and neck histopathology. Diagn. Histopathol., 21(2):77-84, 2015.

Muñoz, N.; Bosch, F. X.; de Sanjosé, S.; Herrero, R.; Castellsagué, X.; Shah, K. V.; Snijders, P. J.; Meijer, C. J. \& International Agency for Research on Cancer Multicenter Cervical Cancer Study Group. Epidemiologic classification of human papillomavirus types associated with cervical cancer. N. Engl. J. Med., 348(6):518-27, 2003.

Ndiaye, C.; Mena, M.; Alemany, L.; Arbyn, M.; Castellsagué, X.; Laporte, L.: Bosch, F. X.; de Sanjosé, S. \& Trottier, H. HPV DNA, E6/E7 mRNA, and p16INK4a detection in head and neck cancers: a systematic review and metaanalysis. Lancet Oncol., 15(12):1319-31, 2014.

Neville, B. W.; Damm, D. D.; Allen, C. M.; Bouquot, J. E. Oral and Maxillofacial Pathology. $3^{\text {rd }}$ ed. Saunders Elsevier, 2009.

Patil, S.; Rao, R. S.; Amrutha, N. \& Sanketh, D. S. Analysis of human papilloma virus in oral squamous cell carcinoma using p16: An immunohistochemical study. J. Int. Soc. Prev. Community Dent., 4(1):61-6, 2014.

Piña-Sánchez, P. \& Alvarado-Cabrero, I. Infección del virus del papiloma humano como un factor de riesgo para carcinoma de células escamosas de cabeza y cuello. Gac. Mex. Oncol., 11(3):175-81, 2012. 
Powell, N. G. \& Evans, M. Human papillomavirus-associated head and neck cancer: oncogenic mechanisms, epidemiology and clinical behaviour. Diagn. Histopathol., 21(2):49-64, 2015.

Psyrri, A.; Sasaki, C.; Vassilakopoulou, M.; Dimitriadis, G. \& Rampias, T. Future directions in research, treatment and prevention of HPV-related squamous cell carcinoma of the head and neck. Head Neck Pathol., 6(Suppl. 1):S1218, 2012

Ramirez, V.; Vásquez-Rozas, P. \& Ramírez-Eyraud, P. Mortalidad por cáncer oral y faríngeo en Chile, años 20022010. Rev. Clin. Periodoncia Implantol. Rehabil. Oral, 8(2):133-8, 2015.

Rethman, M. P.; Carpenter, W.; Cohen, E. E.; Epstein, J.; Evans, C. A.; Flaitz, C. M.; Graham, F. J.; Hujoel, P. P.; Kalmar, J. R.; Koch, W. M.; Lambert, P. M.; Lingen, M. W.; Oettmeier, B. W. Jr., Patton, L. L.; Perkins, D.; Reid, B. C.; Sciubba, J. J.; Tomar, S. L.; Wyatt, A.D. Jr.; Aravamudhan, K.; Frantsve-Hawley, J.; Cleveland, J. L.; Meyer, D. M. \& American Dental Association Council on Scientific Affairs Expert Panel on Screening for Oral Squamous Cell Carcinomas. Evidence-based clinical recommendations regarding screening for oral squamous cell carcinomas. $J$. Am. Dent. Assoc., 141(5):509-20, 2010.

Riera, S. P. \& Martínez, R. B. Morbilidad y mortalidad por cáncer oral y faríngeo en Chile. Rev. Med. Chile., 133(5):555-63, 2005.

Rivera, Z. R.; Delgado, D. J.; Painel, P. V.; Barrero, P. R. \& Larraín, H. A. Mecanismo de infección y transformación neoplásica producido por virus papiloma humano en el epitelio cervical. Rev. Chil. Obstet. Ginecol., 71(2):13540, 2006.

Robinson, M.; Schache, A.; Sloan, P. \& Thavaraj, S. HPV specific testing: a requirement for oropharyngeal squamous cell carcinoma patients. Head Neck Pathol., 6(Suppl. 1):S83-90, 2012.

Ruiz, G.; Ojeda, P. \& Di Giampietro, L. Determinación del VPH en cavidad oral por técnica del hisopo. Rev. Venez. Oncol., 21(2):70-6, 2009.

Sapp, J. P.; Eversole, L. R. \& Wysocki, G. P. Patología Oral y Maxilofacial Contemporánea. $2^{a}$ ed. Madrid, Elsevier, 2005.

Serena-Gómez, E.; Bologna-Molina, R. E.; Nevarez-Rascon, A. \& Rocha-Buelvas, A. HPV prevalence on malignant lesion process of the upper aerodigestive tract. Int. J. Odontostomat., 5(1):5-12, 2011.

Syrjänen, K. J.; Pyrhönen, S. \& Syrjänen, S. M. Evidence suggesting human papillomavirus (HPV) etiology for the squamous cell papilloma of the paranasal sinus. Arch. Geschwulstforsch., 53(1):77-82, 1983.
Thomas, J. \& Primeaux, T. Is p16 immunohistochemistry a more cost-effective method for identification of human papilloma virus-associated head and neck squamous cell carcinoma? Ann. Diagn. Pathol., 16(2):91-9, 2012.

Westra, W. H. Detection of human papillomavirus (HPV) in clinical samples: evolving methods and strategies for the accurate determination of HPV status of head and neck carcinomas. Oral Oncol., 50(9):771-9, 2014.

zur Hausen, $\mathrm{H}$. Condylomata acuminata and human genital cancer. Cancer Res., 36(2 pt. 2):794, 1976.

zur Hausen, H. Papillomaviruses causing cancer: evasion from host-cell control in early events in carcinogenesis. J. Natl. Cancer Inst., 92(9):690-8, 2000.

zur Hausen, H.; Meinhof, W.; Scheiber, W. \& Bornkamm, G. W. Attempts to detect virus-secific DNA in human tumors. I. Nucleic acid hybridizations with complementary RNA of human wart virus. Int. J. Cancer, 13(5):650-6, 1974.

Dirección para Correspondencia:

Dr. William Contreras

Departamento de Ciencias Básicas Biomédicas

Facultad de Ciencias de la Salud

Universidad de Talca

Avenida Lircay s/n

Región del Maule

Talca

CHILE

Email: wicontreras@utalca.cl

Recibido: 26-06-2015

Aceptado: 08-09-2015 